\title{
ENCUENTRO DE PALABRAS: UN ANÁLISIS LITERARIO DEL CUENTO SOBRE LAS PLUMAS DEL PAVO, DE AGUSTÍN MONSREAL
}

\author{
Elvia Estefanía López Vera \\ Universidad Veracruzana (México) \\ elvlopez@uv.mx
}

Recibido: 19/02/2019 - Aprobado: 27/06/2019

DOI: doi.org/10.17533/udea.lyl.n76a07

\begin{abstract}
Resumen: Se plantea el análisis literario del cuento Sobre las plumas del pavo, del escritor mexicano Agustín Monsreal. Se estudia la técnica del retrato literario a través de las palabras compuestas, las cuales sintetizan elementos de la prosopografía y la etopeya en la configuración de los dos protagonistas. Luego, se enfatiza en la interacción de los personajes, con el fin de dominar al otro. Esta lucha de poder fundamenta la dialéctica del relato entre el deseo y el rechazo, la expectativa y la realidad, el encuentro y el desencuentro, y el crecimiento y el aniquilamiento.
\end{abstract}

Palabras clave: cuento; Hispanoamérica; literatura; narrativa; análisis; palabras compuestas.

\section{ENCOUNTER OF WORDS: A LITERARY ANALYSIS OF THE STORY SOBRE LAS PLUMAS DEL PAVO, BY AGUSTIN MONSREAL}

Summary: The literary analysis of the story Sobre las plumas del pavo, by the Mexican writer Agustín Monsreal, is proposed. The technique of literary portraiture is studied through the composite words, which synthesize elements of prosopography and ethopreia in the configuration of the two protagonists. Then, it emphasizes the interaction of the characters, in order to dominate the other. This power struggle underpins the narrative's dialectic between desire and rejection, expectation and reality, encounter and disagreement, and growth and annihilation.

Key words: story; Hispanic America; literature; narrative; analysis; compound words.

LINGÜÍSTICA Y LITERATURA 
Si Agustín Monsreal logra un lenguaje popularmente poético y con un ritmo que jamás desfallece causarnos tal desazón es porque se trata de un escritor genuino.

Elena Poniatowska

\section{Introducción}

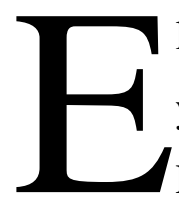

1 presente artículo pretende abonar al estudio de la obra narrativa del escritor

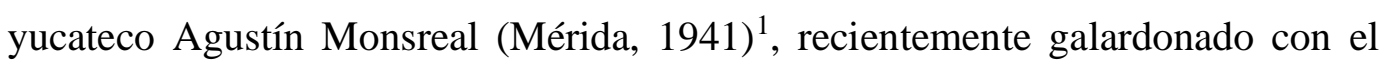
Premio Iberoamericano de Minificción Juan José Arreola 2018 por su trayectoria como cuentista y editor. A lo largo de su trayectoria como narrador y como poeta ha definido un estilo sobresaliente en la marejada de escritores nacidos a partir de la década de los años cuarenta, cuya propuesta gira en torno a los problemas de la vida cotidiana, vistos desde la crudeza del hartazgo y la resignación.

La literatura hispanoamericana de la segunda mitad del siglo XX se caracterizó por una ferviente iniciativa experimental, como una resonancia del oleaje violento de las vanguardias y de las dos guerras mundiales. En la revolución artística y cultural de los años setenta, los escritores apostaron por cuestionar los géneros literarios y el lenguaje que los vertebra, para reinventar perspectivas sociales, culturales y políticas que representaran la diversidad de Hispanoamérica.

Ejemplos ineludibles como el boom latinoamericano fueron escuela para nuevos autores y para nuevos lectores (Oviedo 2001: 300), quienes no se conformaron con leer la realidad desde su punto de vista ni desde la limitante óptica del poder. La narración ficticia de espacios de libertad — como un pueblo tropical o una ciudad aletargada — trazó la identidad de esos nuevos lectores, que se leyeron a sí mismos como en un espejo desempañado.

La obra narrativa de Agustín Monsreal ha sido valorada como una de las más importantes en los últimos cincuenta años. Su estilo se distingue por una composición virtuosa, fluida y ágil, con un tono que provoca al lector mediante la ruptura de lo

1. Un agradecimiento de manera especial a la generosidad del escritor Agustín Monsreal para la revisión del manuscrito de este artículo. Se espera contribuir de algún modo a la difusión de su obra, así como a la valoración de su narrativa dentro y fuera de México.

LINGÜÍSTICA Y LITERATURA 
cotidiano. Ajeno a la novela, como lo fue también Borges, Monsreal nació como escritor en un ambiente literario donde se buscaba el diálogo entre el cuento y el ensayo. Su prosa desafiante retoma la fuerza narrativa de grandes cuentistas como Julio Torri o Juan José Arreola para crear un estilo propio, con el que Monsreal se ha ganado un lugar destacado como autor de cuentos breves.

En 1979, Agustín Monsreal publicó el libro de cuentos Los ángeles enfermos, obra con la cual obtuvo el Premio Nacional de Cuento 1978, otorgado por el Instituto Nacional de Bellas Artes y la Casa de la Cultura de San Luis Potosí. En dicho libro, Monsreal muestra que las tragedias de la existencia no están únicamente en los momentos decisivos de la vida, sino que se presentan en cada aliento. Con ello, se integró a las tendencias literarias del momento por la rememoración de las reflexiones kafkianas sobre la fragilidad de la existencia y la vulnerabilidad de ser humano frente a sí mismo. Esto se dio dentro de una corriente literaria que cuestionaba la incorporación del hombre a la sociedad y sus avatares; a la que también abonaron, por ejemplo, autores como José Emilio Pacheco con el conflicto entre el hombre y la ciudad.

En 1983, con Sueños de segunda mano, Monsreal dio tratamiento a los asuntos de la cotidianidad que, por su monotonía, pueden aniquilar a cualquiera. Sin duda, es a partir de este libro cuando Monsreal consolida su estilo como cuentista, inconfundible por la habilidad narrativa fusionada con una pluma ensayística y por la creatividad para convertir frases sabidas en construcciones que, por ingeniosas, se quedan en la mente del atento lector.

En esa misma década, La banda de los enanos calvos (1987) salió a la luz como un conjunto de cuentos que representa una continuidad con la propuesta del anterior, específicamente sobre la cómoda rutina como un recurso para evadir el esfuerzo, lo cual resuena en una sociedad que no motiva a nadie a innovar ni a trascender.

Dicho libro acentúa una protesta contra la existencia vacía de personajes que caen en el conformismo, particularmente en ámbitos como la creación artística. Una de las constantes creativas en Monsreal es la del escritor como personaje-protagonista, con una escritura 
lúdica (Quintana 2014, p. 4) la cual recrea escenarios de seducción, de conflicto amoroso o social.

Su obra «imaginativa pero también terrenal y corrosiva» (Torres 2010, p. 4), planteó una crítica a los ambientes del arte que con frecuencia están representados por intelectuales estancados en sus propuestas estéticas, cerrados al diálogo con la crítica, ensimismados en su aporte y cegados por su vanidad. En esta última veta se puede insertar el cuento Sobre las plumas del pavo (1987), el cual tiene como narrador-personaje a un escritor encumbrado que accede a conocer a una de sus admiradoras.

El título Sobre las plumas del pavo alude al relato de las acciones de conquista del narrador del cuento, que toma el rol de cortejo en un encuentro con una joven. Las acciones de galanteo se relacionan con las características del pavo como un ave que se destaca por su belleza, refinamiento y vanidad; por lo tanto, un cuento acerca del plumaje de un pavo puede entenderse como la narración de las experiencias del narrador-personaje en las cuales se muestra vanagloriado y admirado por otros personajes, como una expresión similar a la de las rayas del tigre.

Pero, ¿por qué un pavo y no un tigre? La ambigüedad que genera el título abre las posibilidades de interpretación del cuento pues, si se atiende al significado que se le da al pavo en países como España (pavo como tonto o poco sagaz), se puede inferir que el cuento no va a narrar las batallas ganadas, sino las perdidas: esto podría tener sentido en el texto cuando las intenciones del narrador-personaje de intimar con Casiopea no se consuman. Del mismo modo, la coherencia del título con el desarrollo del cuento se observa al final, cuando Casiopea animaliza al narrador-personaje no como un pavo, sino como un gusano, un piojo, una rata, una cucaracha, un sapo y una araña. Dicho esto, como se verá más adelante, tiene la clara intención de configurarlo inferior a ella.

Según el planteamiento de este artículo, el uso de palabras compuestas y el manejo preciso del estilo directo permite estudiar el juego de roles de dominación de los dos personajes en conflicto. Tales elementos —entendidos aquí como recursos literarios-, permiten al narrador-personaje configurar a Casiopea y a su espacio íntimo, mientras que a 
ella la posibilitan para expresar el rechazo a las intenciones sexuales del narradorpersonaje, con el mismo código léxico-semántico de palabras compuestas que él emplea.

En un juego de perspectivas bien logrado, el argumento principal del cuento objeto de este análisis confronta dos posturas con expectativas distintas: la joven Casiopea es una personaje que seduce sin querer, pero no permite ser seducida: busca reunirse con el escritor reconocido para entrar en su círculo literario; mientras tanto, el narrador-personaje prepara tanto al público lector como a sí mismo para un encuentro sexual con Casiopea, que no sucede por el rechazo de ella. Por ello, el encuentro de ambos personajes se consuma en desencuentro.

Un elemento destacado en Sobre las plumas del pavo es la presencia de palabras compuestas que no solo sorprenden al lector con el manejo original del léxico y la semántica, pues dichas palabras no son comunes en la expresión popular; sino que también sostienen el argumento del cuento, el mismo que he apuntado en el párrafo anterior. ¿Cómo logra Monsreal conectar la forma y el contenido en el cuento Sobre las plumas del pavo? Este artículo se enfoca en el estudio de las palabras compuestas registradas en el cuento en dos niveles de análisis: a) en el nivel léxico, se parte de la idea de que este recurso complejiza la configuración de los personajes, porque condensa en una palabra compuesta la técnica del retrato; y, b) en cuanto al análisis narrativo, las palabras compuestas del cuento en conjunto sustentan un juego de roles de dominación que se invierte al final del cuento.

\section{El análisis léxico-semántico en la técnica del retrato literario}

La técnica del retrato literario se basa principalmente en dos conceptos aristotélicos: prosopografía, - la descripción física del personaje - que se referiere a: a) elementos corporales: estatura, peso corporal, color de piel o raza, tono y corte de cabello, color de ojos; b) elementos del vestido: atuendo, moda de la época, accesorios, representación, disfraces; c) registro lingüístico: palabras que el personaje presenta en el eje paradigmático, así como las posibilidades de significación en el nivel sintagmático. En cuanto al registro 
lingüístico, la prosopografía puede abarcar desde lo que el retrato sugiere en el estilo indirecto, es decir, en voz del narrador, o lo que el mismo personaje enuncia en estilo directo para configurarse o para retratar a otro personaje (Estébanez 1999, p. 933).

Por su parte, la etopeya agrupa los recursos psicológicos de carácter y comportamiento del personaje literario. El autor selecciona cada elemento de la etopeya para que dicho personaje se relacione con otros personajes y, a la vez, tenga su identidad propia ante él mismo y con respecto a la visión de los demás. La configuración del carácter también puede rastrearse por estar conectado con simbolismos existentes en el relato, como el color de la vestimenta del personaje, el cual puede reflejar un rasgo de su personalidad, su actitud ante la vida o una ideología.

Para Aristóteles, la prosopografía y la etopeya representan el equilibrio del cosmos entre el ser y el parecer. Monsreal, consciente de esta premisa, explota el recurso de las palabras compuestas para fusionar un elemento de la prosopografía y un elemento de la etopeya en palabras como cabellimedusiana y ojidominadora, las cuales condensan características físicas, como el cabello o los ojos, con actitudes de dominación, como el mito medusiano.

El cuento Sobre las plumas del pavo está conformado por 31 palabras compuestas que, según el planteamiento principal de este artículo, son empleadas por ambos personajes de manera estratégica en momentos clave para imponerse frente al otro personaje. Dichas palabras compuestas aportan complejidad narrativa, porque su valor no se acaba en el nivel descriptivo de la configuración de los personajes, sino que la construcción artística de cada palabra se complementa con su posición dentro de la trama. Además, acuñan una función narrativa trascendente para el argumento del cuento, que muestra a los personajes en una esgrima verbal, cuya premisa es la dominación del otro a través de la satisfacción del deseo, ya sea sexual o intelectual.

Para valorar la importancia de las palabras compuestas en el cuento de Monsreal, me he propuesto destacarlas en el nivel léxico-semántico. Para este fin, he clasificado las 31 palabras compuestas en cuatro grupos:

a) Palabras compuestas con las que el narrador configura a Casiopea y, en el último caso, a su poesía; 
b) Palabras compuestas con las que el narrador-personaje se autodenomina, así como es denominado por Casiopea en un caso;

c) Palabras compuestas que emplea el narrador-personaje para configurar a Casiopea en el acto sexual idealizado por él y;

d) Palabras compuestas que utiliza el narrador-personaje para caracterizar actitudes propias respecto a la poesía de Casiopea.

A continuación, aparece el listado de las palabras compuestas empleadas en el cuento de Monsreal, por orden de aparición y clasificadas de acuerdo con las categorías especificadas anteriormente:

a) Palabras compuestas con las que el narrador configura a Casiopea y, en el último caso, a su poesía:

-ojidominadora

-narielénica

- boquisuculenta

-cuellicisnácea

-pechidelicias

- cinturiavispada

- caderienérgica

- glutipasmante

—muslimanjares

- chamurriexquisita

- casquiligera

—manilúdica

- carnientrona

-ricurigualada

- gueishiencantadora

—revanchimujeril 
b) Palabras compuestas con las que el narrador-personaje se autodenomina, así como es denominado por Casiopea en un caso:

-poetilaureado

- glorinacional

- machihalagado

-calenturientiarremetedor

-clasiconocedor

- carilascivo

- gestibabeante

-poetiglorioso

c) Palabras compuestas que emplea el narrador-personaje para configurar a Casiopea en el acto sexual idealizado por él:

- boquifuente

- pechiabrevadero

- caderiensamble

-carnientrega

d) Palabras compuestas que utiliza el narrador-personaje para caracterizar actitudes propias respecto a la poesía de Casiopea:

- burlifranqueza

- cabeciaprobatoriamente

En la clasificación anteriormente expuesta puede observarse que es el personaje de Casiopea el que cuenta con mayor número de palabras (17 de 31), lo que indica la intención del narrador-personaje por retratar predominantemente a Casiopea según su perspectiva. Esto es relevante si lo se compara con la cantidad que el narrador-personaje utiliza para autodenominarse (8 de 31), cifra que es la mitad de las empleadas por él para Casiopea. 
Sin embargo, los números resultan más significativos cuando se comparan la cantidad de palabras compuestas enunciadas por el narrador (30 de 31) con la que manifiesta en estilo directo el personaje de Casiopea (1 de 31), que se localiza en la parte final del cuento y por eso aparece en la lista b), porque configura al narrador poetiglorioso. De este modo, esta palabra compuesta tiene importancia especial por ser la única que Casiopea enuncia para referirse a su interlocutor con desdén, después de que este intentara intimar con ella. Más adelante, se retomará esta palabra compuesta por su pertinencia en el giro narrativo del desenlace.

Dentro de las 15 palabras compuestas para Casiopea enlistadas en la lista a), es posible realizar otra clasificación interna: por ejemplo, aquellas palabras que contienen un elemento de la prosopografía con un referente griego de seducción femenina (cabellimedusiana, narielénica); las que combinan un elemento de la prosopografía con una actitud pasional (ojidominadora, casquiligera, manilúdica, carnientrona, ricurigualada, caderienérgica, glutipasmante, gueishiencantadora); las que fusionan un elemento de la prosopografía con el sentido del gusto (boquisuculenta, pechidelicias, muslimanjares, chamurriexquisita); y las que muestran un elemento de la prosopografía con una silueta animal que simboliza sensualidad (cuellicisnácea, cinturiavispada).

La construcción de las palabras clasificadas anteriormente responde a un patrón que coloca en primer lugar un rasgo físico y en segundo lugar un adjetivo calificativo. De esta manera, Casiopea es, en esencia, lo que el narrador-personaje puede percibir por la vista y por su apreciación personal, pero no por lo que ella puede significar para sí misma. Esta visión parcial es ofrecida así al lector no para limitar su perspectiva de Casiopea, sino con el fin de advertirlo de que se trata de una idealización de una imagen creada por el narrador-personaje para su deleite. En esta mirada, las palabras compuestas son un recurso retórico que llama la atención del lector, al tiempo que le da profundidad a la configuración de Casiopea desde el punto de vista de otro personaje.

En cuanto a la lista b), las palabras compuestas que refieren al narrador personaje pueden agruparse en las que lo destacan como intelectual (poetilaureado, glorinacional, machihalagado, clasiconocedor, poetiglorioso) y en las que lo configuran como un 
personaje instintivo, alentado por el deseo carnal (calenturientiarremetedor, carilascivo, gestibabeante).

En esta última línea se vincula la tercera clasificación, dado que los elementos de la lista c) concuerdan dentro de la trama con el momento en el que el narrador-personaje idealiza el cuerpo de Casiopea, pues lo configura receptivo para el acto sexual con palabras compuestas que indican la entrega de ella desde la perspectiva del narrador (boquifuente, pechiabrevadero, caderiensamble, carnientrega); no obstante, este deseo carnal del narrador hacia Casiopea se muestra puro a través del atuendo blanco del narradorpersonaje.

En este aspecto se destaca que la intención sexual sólo está presente en la voz narrativa, y luego, en las líneas siguientes, el lector sabrá que no es correspondida por Casiopea, por lo que resulta significativa para este análisis literario la comprensión de la disparidad de las intenciones del narrador-personaje frente a las de ella. A pesar de que el contacto de los cuerpos no tiene inicio por el rechazo de Casiopea, es un ejercicio interesante la comparación entre las palabras compuestas de ella frente a las de él: Casiopea es configurada como bella, seductora y receptiva, mientras que la configuración de él tiene elementos de raciocinio que finalmente se degradan por el deseo y son vencidos por el rechazo de ella.

La breve lista del grupo d) se considera por aparte, ya que hace referencia a las palabras compuestas que muestran la actitud del narrador-personaje hacia la poesía de Casiopea. Esta lista es contrastante con la del grupo c), en el que se idealiza el acto sexual; en cambio, la labor intelectual de Casiopea es vista por el narrador-personaje con burlifranqueza y cabeciaprobatoriamente. En el apartado siguiente, analizaré las diferencias de tratamiento de los aspectos intelectual y sexual de Casiopea, según los indicios que arroja la perspectiva del narrador-personaje.

\section{La función de las palabras compuestas en la trama: la inversión de roles de dominación}


El cuento Sobre las plumas del pavo puede dividirse en tres momentos narrativos: 1) antes del encuentro, 2) durante el encuentro y 3) el rechazo de una de las partes. Mi propuesta de segmentación del cuento se basa en los matices que ofrece la voz narrativa en primera y en tercera persona por parte del narrador-personaje. El narrador, un reconocido poeta, se muestra seguro de sí mismo cuando en la primera parte retrata a Casiopea como una mujer atractiva y estimulante, en una idealización que responde más a su deseo que a la convivencia con la chica.

En el segundo momento, el poeta y Casiopea logran reunirse: se presentan uno al otro en el umbral de la puerta del departamento de ella, en la línea de su intimidad. Dentro de ese lugar en el que habita Casiopea, el poeta busca el contacto físico; pero ella lo rechaza. En este punto surge el clímax del cuento: el desencuentro de perspectivas, considerando el tercer momento, en el que el narrador-personaje muestra su iniciativa para un encuentro íntimo, mientras que Casiopea busca compartir sus poemas con el escritor encumbrado para lograr su difusión en el ambiente literario.

A partir de esta división tripartita, considero que son más claros los matices en la configuración de los personajes protagónicos. Los tres momentos presentan palabras compuestas con cantidades equilibradas en las dos primeras (15 en la primera parte y 15 en la segunda parte), con el empleo de una sola en la tercera parte. Pero no es la cuantificación de las palabras lo que permite advertir este cambio, sino quién y en qué contexto enuncia esas palabras compuestas.

La percepción del narrador-personaje hacia Casiopea es dominante en el relato, pero en la parte final surge un cambio en esta dinámica en la narración en voz del personaje masculino. Casiopea se refiere en estilo directo al personaje masculino para rechazarlo en sus intenciones de intimar. En este artículo, esta ruptura tiene el nombre de dialéctica del encuentro y desencuentro, la cual ya se explicó a partir del manejo de palabras compuestas.

En las dos primeras partes, se subraya el auto posicionamiento casi épico del narradorpersonaje como orientador y salvador de la incipiente carrera de Casiopea en el mundo de las letras. Primero, el narrador-personaje toma la voz que representa a la masculinidad que 
no ha sabido ver más allá de lo físico en Casiopea, en palabras textuales tomadas del mismo cuento:

Se notaba que a la inocente criatura le había ido muy mal en su trato con los hombres. Que, sin duda, confundidos por los valores aparentes y pasajeros de lo externo (;oh lamentable ceguera masculina!), ninguno había sabido hallar. ¡Vamos! Ni siquiera sospechar el prodigioso universo espiritual, el caudal humano que albergaba en el interior de Casiopea.

Como consuelo - con ese toque de ironía que es uno de los rasgos principales de la narrativa de Monsreal-, el narrador-personaje le explica a Casiopea que «una mujer es un ser que ha encontrado su propia naturaleza. Tú la buscas: eres virgen». Con esta referencia explícita a Girardot, el narrador-personaje busca trazar el puente entre la lectura de poesía de Casiopea (el ámbito intelectual) y su deseo de un encuentro sexual con ella (el ámbito sexual), ofreciéndole su orientación en ese camino de búsqueda de su feminidad y de su madurez intelectual.

La perspectiva que el narrador-personaje muestra a Casiopea la configura como una «cachorrita ingenua [que necesitaba a] un hombre que le ayudara a encontrarse consigo misma, un maestro, un guía, un varón solícito, maduro, cariñoso, tierno, comprensivo, experimentado, carilascivo, gestibabeante». Hasta cierto punto, la «virginidad» intelectual de Casiopea, subrayada por el narrador-personaje, funciona como un eufemismo para indicar su falta de talento como poetisa; pero, al mismo tiempo, alude a una iniciación sexual que no ha sido del todo consumada porque ningún hombre ha sabido descubrir su interior por esa «ceguera masculina».

No obstante, con su actitud compasiva, el narrador-personaje da indicios de que sus palabras en el cortejo a Casiopea son solo apariencia: «-Aquí me tienes rendido a tus pies- y mi rodilla nunca tocó el suelo». Esta línea se convierte en una clave de lectura para este análisis, pues da una pauta para señalar que el discurso del narrador-personaje es idílico dentro de código del amor cortés que, con la rendición ante su amada, logra conquistarla; pero, para el caso del cuento de Monsreal, la fórmula está enmarcada con anotaciones que la voz narrativa añade para evidenciar la falsedad de su entrega a Casiopea como la de «mi rodilla nunca tocó el suelo». 
El tercer momento es el de mayor tensión narrativa, porque se asemeja a una esgrima. Aun con la cadencia de la música clásica de fondo, la disonancia de los cuerpos está subrayada por la mención de dos músicos (Gustav Mahler y Serguéi Prokofiev) con dos matices musicales distintos y con dos ideologías polarizadas en tiempos de guerra. Dicha alusión no es fortuita, dado que anuncia una ruptura entre los personajes quienes, a manera de contrapunto, sostienen sus expectativas sobre el encuentro: íntimo, por parte de él; de difusión de su poesía, por parte de ella.

En esta propuesta analítica, dentro del tercer momento narrativo, el juego de roles de dominación se invierte: hacia el final del texto, la intervención en estilo directo por parte de Casiopea es pertinente para el rechazo, pues ella usa por primer y única vez el recurso retórico de la palabra compuesta para referirse al escritor: «- ¿Sabes qué, poetiglorioso? - Masculló imponiéndome su fiera estatura y conteniendo a duras penas el enronquecimiento pasional de la voz. Estoy harta de los imbéciles, de los enanos ridículos como tú». El empleo de la palabra compuesta poetiglorioso reconduce el relato como intervención del personaje femenino, porque en el momento en que Casiopea toma la voz y utiliza dicha composición léxica, retoma un estilo que la sublima. De ese modo, penetra en la mente de su opuesto y lo debilita.

Y así como en una esgrima verbal, Casiopea triunfa, porque logra trascender los límites de lo enunciado al profundizar en la mente del otro e imitar su registro lingüístico, para usarlo a su favor y liberarse del acecho. Sin embargo, el triunfo de Casiopea es efímero, pues su desdén será sancionado por el narrador-personaje. De acuerdo con la mitología griega — de la que se ha retomado su nombre-, Casiopea es símbolo de belleza y perennidad, así como de vanidad y sufrimiento. Por burlar a Poseidón, cumple una condena eterna sentada en un trono cuya silueta es identificada con la constelación que lleva su nombre. Asimismo, la Casiopea del cuento de Monsreal desató la ira del escritor que está en la cima de su trayectoria, por lo que tendrá que aceptar su destino lejos de su benevolencia.

En una lectura desde el erotismo, puede decirse que el eros platónico guía el relato durante las dos primeras partes, pues el escritor encumbrado narra los hechos desde una 
idealización de Casiopea, planteándose él mismo como objeto del deseo que no se puede negar al encuentro sugerido. En la tercera parte, no es el amor ni el acto sexual el que sublima Casiopea, sino el haberse incorporado a la dimensión retórica del escritor para transformar el mismo discurso y manipularlo para posicionarse frente al narradorpersonaje.

El viraje discursivo de Casiopea conforma un desenlace sorpresivo digno del cuento como género narrativo breve, en el cual el atento lector puede suponer el rechazo de ella hacia el narrador-personaje, pero no se espera que sea Casiopea quien lo nombre poetiglorioso a manera de imitación sarcástica del registro lingüístico de su contraparte. Asimismo, el análisis que propongo permite comprender que el estilo directo en el que Casiopea enuncia dicha palabra compuesta revierte la perspectiva de un narrador: no se trata únicamente de la voz del narrador, sino también de la voz de ella en una trama construida por él.

Asimismo, es pertinente prestar atención a las palabras simples que enumera Casiopea para referirse al personaje masculino: «metamorfoseada en energúmena, me llamó piltrafa miserable y andrajo de porquería y pedazo de estiércol y gusano y piojo y rata y cucaracha de albañal y sapo inmundo y araña grasienta». Si bien estas palabras no están todas enunciadas en estilo directo ni son compuestas, tienen en común una intención de mostrar superior a Casiopea. A pesar de su transformación en energúmena, Casiopea mantiene su condición humana, al tiempo que animaliza a su interlocutor con animales que connotan repugnancia, tales como los gusanos, los piojos, las ratas, las cucarachas, los sapos y las arañas.

Como desenlace, el poetiglorioso escritor nulifica toda posibilidad de apoyo a Casiopea en su trayectoria como poetisa, lo que significa el aniquilamiento del otro desde su posición de poder intelectual. Al cierre del cuento, el narrador-personaje se salva del naufragio. Se muestra altisonante, victorioso, eminente y renovado. Sin embargo, esto es nuevamente una apariencia, porque en la anulación de posibles becas y publicaciones para Casiopea subyace la derrota del narrador-personaje. Casiopea lo ha descubierto vulnerable y mediocre en su 
propio juego de palabras. Esto abre otras posibilidades de lectura desde el personaje de Casiopea y su papel feminista, que pueden desarrollarse en investigaciones futuras.

\section{Conclusión}

Para concluir, es importante considerar que la función de las palabras compuestas en el cuento Sobre las plumas del pavo es un recurso literario que fortalece la forma y el contenido del relato. Así como le da complejidad a la configuración de los personajes, representa un sesgo aristotélico en busca del equilibrio entre la forma y el contenido, entre el cuerpo y la mente, y entre la pasión y la razón.

Dichos elementos pueden identificarse en el nivel de la configuración de los personajes y en el nivel de las acciones. El narrador-personaje logró transformar el lenguaje para su beneficio, derribó las barreras de la denotación y se resignificó para contar su punto de vista. Por su parte, Casiopea jugó con las mismas cartas, aunque esperó paciente el momento oportuno para mostrar que conocía y dominaba la técnica de su conquistador.

Por último, también es importante señalar que, aunque el uso de palabras compuestas como recurso narrativo no es una constante en la obra de Monsreal ni se trata de un recurso imprescindible en su valorada producción cuentística, se puede afirmar que forma parte de un estilo experimental que sostiene la originalidad de su obra narrativa.

¿Puede decirse que Monsreal creó un lenguaje nuevo con el uso de palabras compuestas? Como narrador instruido, Monsreal redimió el lenguaje que le fue heredado para impulsar la trama y complejizar la perspectiva del narrador de Sobre las plumas del pavo. En otras palabras, como hijo de una larga tradición conceptista, retomó el significado de cada palabra para darle una dimensión superior. La unión y el desencuentro entre dos elementos que se atraen, bien sean palabras o cuerpos.

\section{Referencias bibliográficas}


1. Bataille, G. (2015). Historia del erotismo. Javier Palacio Tauste (Trad.). Madrid: Errata naturae.

2. Estébanez Calderón, D. (1999). Diccionario de términos literarios. Madrid: Alianza.

3. Monsreal, A. (1987). La banda de los enanos calvos. México: SEP/Lecturas mexicanas.

4. Oviedo, J. M. (2001). Historia de la literatura hispanoamericana, 4. De Borges al presente, Madrid: Alianza.

5. Quintana Gómez, M. (2014). El cuento es un regalo que nos da la literatura. Entrevista a Agustín Monsreal. Revista digital universitaria, 15(12), s/p. Recuperado de http://www.revista.unam.mx/vol.15/num12/art99

6. Torres, F. (2010). Nota introductoria. Agustín Monsreal. Selección y nota introductoria de Vicente Francisco Torres. México: Material de Lectura UNAM/ serie El Cuento Contemporáneo. 